\title{
Beneficial bacteria activate nutrients and promote wheat growth under conditions of reduced fertilizer application
}

\author{
Juanjuan Wang ${ }^{2 \dagger}$, Ruochen $\mathrm{Li}^{2 \dagger}$, Hui Zhang ${ }^{2}$, Gehong Wei ${ }^{1,2}$ and Zhefei $\mathrm{Li}^{2^{*}}$ (D)
}

\begin{abstract}
Background: Excessive application of chemical fertilizer has exerted a great threat to soil quality and the environment. The inoculation of plants with plant-growth-promoting rhizobacteria (PGPR) has emerged as a great prospect for ecosystem recovery. The aim of this work to isolate PGPRs and highlights the effect of bacterial inoculants on available N/P/K content in soil and on the growth of wheat under conditions of reduced fertilizer application.

Results: Thirty-nine PGPRs were isolated and tested for their growth-promoting potential. Thirteen isolates had nitrogen fixation ability, of which N9 (Azotobacter chroococcum) had the highest acetylene reduction activity of $156.26 \mathrm{nmol} / \mathrm{gh}$. Eleven isolates had efficient phosphate solubilizing ability, of which P5 (Klebsiella variicola) released the most available phosphorus in liquid medium (231.68 mg/L). Fifteen isolates had efficient potassium solubilizing ability, of which K13 (Rhizobium larrymoorei) released the most available potassium in liquid medium (224.66 mg/L). In culture medium supplemented with tryptophan, P9 (Klebsiella pneumoniae) produced the greatest amount of IAA. Inoculation with the bacterial combination $\mathrm{K} 14+176+\mathrm{P} 9+\mathrm{N} 8+\mathrm{P} 5$ increased the alkali-hydrolysed nitrogen, available phosphorus and available potassium in the soil by $49.46,99.51$ and $19.38 \%$, respectively, and enhanced the N, P, and K content of wheat by $97.7,96.4$ and $42.1 \%$, respectively. Moreover, reducing fertilizer application by $25 \%$ did not decrease the available nitrogen, phosphorus, and potassium in the soil and N/P/K content, plant height, and dry weight of wheat.
\end{abstract}

Conclusions: The bacterial combination K14 + 176 + P9 + N8 + P5 is superior candidates for biofertilizers that may reduce chemical fertilizer application without influencing the normal growth of wheat.

Keywords: Plant growth-promoting rhizobacteria, Phosphate-solubilizing, Potassium-solubilizing, Nitrogen fixation, Promote

\section{Background}

China has the largest population in the world.The application of chemical fertilizer has played a key role in increasing grain production in China to produce sufficient food for a very large population with limited arable land [1]. In recent decades, to meet the nutritional needs of a rapidly growing population, China's the annual total demand for chemical fertilizers has shown an upward trend; that country has become the largest manufacturer

\footnotetext{
* Correspondence: lizhefei@hotmail.com

†Juanjuan Wang and Ruochen Li contributed equally to this work.

${ }^{2}$ Shaanxi Key Laboratory of Agricultural and Environmental Microbiology,

College of Life Science, Northwest A\&F University, Yangling, Shaanxi, China

Full list of author information is available at the end of the article
}

and consumer of chemical fertilizers, accounting for onethird of the global total consumption [2]. For example, from 1997 to 2006, the average application of nitrogen fertilizer for rice increased from $145 \mathrm{~kg} / \mathrm{ha}^{-1}$ to $300 \mathrm{~kg} /$ $\mathrm{ha}^{-1}$ in the Taihu region [3], a significantly larger increase than in countries outside China. However, the utilization efficiency of these fertilizers is only $30-40 \%$, indicating that most applied chemical fertilizer is lost by different pathways, such as ammonia $\left(\mathrm{NH}_{3}\right)$ volatilization and leaching [4-6].

Repeated overuse of chemical fertilizer can have a negative effect on soil quality and soil microbial community structure. Excessive fertilizer aggravates the decline of soil organic matter and fertility and accelerates soil 
acidification, which in turn reduces crop yield [7, 8]. Therefore, there is an urgent need to find an environmentally friendly strategy to reduce the application of chemical fertilizer and increase crop yield. In many countries, it is a widely accepted practice to enhance sustainable agricultural production by inoculating crops with plant growth-promoting rhizobacteria (PGPR).

Plant-growth-promoting rhizobacteria are free-living soil microorganisms that inhabit the rhizosphere or plant roots during plant growth and development. PGPR can promote plant growth, help prevent pathogen invasion and improve plant adaptability to abiotic or biological stresses [9-11]. The beneficial effects of PGPR on plants can be explained by different mechanisms, including (1) nitrogen fixation [12]; (2) inorganic phosphate solubilization and organic phosphate mineralization [13]; (3) production of plant growth regulators or phytohormones such as indole-3-acetic acid (IAA), cytokinins, and gibberellins [14, 15]; (4) production of siderophores, 1-amino-cyclopropane-1 -carboxylate (ACC) deaminase, and hydrogen cyanate [16, 17]; (5) and biological control of phytopathogens and insects by synthesizing antibiotics or fungicidal compounds or competiting with detrimental microorganisms $[18,19]$.

Agricultural problems caused by the long-term use of pesticides, fertilizers and other products have become increasingly prominent. This not only pollutes agricultural products but also causes an imbalance in the proportions of various nutrients, the destruction of organic matter in the soil and a decrease in the structural integrity and properties of aggregates, leading to soil compaction, salinization and disease aggravation. However, soil microorganisms are involved in various biotic activities of the soil ecosystem to promote dynamic turnover and sustainable crop production. Thus PGPR and their interactions with plants have great application prospects in ecological agriculture and sustainable agriculture. Coinoculation of cotton with Azotobacter chroococcum strains can positively influence plant growth and reduce nitrogen fertilization doses by $50 \%$ [20]. Korir et al. [21] conducted experiments using a low-phosphorous soil under greenhouse conditions to examine the effect of PGPR on the nodulation and growth of common bean. The results showed that mixed inoculaiton with strains of Bacillus megaterium and Rhizobium tropici significantly increased nodule fresh weight, plant dry weight, and root dry weight by $192.2,124.5$, and $126.7 \%$, respectively.

In northwest China, wheat is a staple food that has special regional importance. Low annual precipitation limits crop growth, and there is much emphasis on the use of large amounts of chemical fertilizer to increase wheat yields. However, information is scarce regarding the isolation of PGPR from the wheat rhizosphere and the role of PGPR in nitrogen fixation, phosphate solubilization, plant growth promotion and reduction of the need for fertilizer in wheat. This study was planned to (1) isolate PGPR from the rhizosphere/roots of wheat and screen them in vitro for plant growth promotion potential; (2) investigate the effect of PGPR on the availability of nitrogen, phosphorus and potassium in soil and the growth of wheat; and (3) evaluate the role of PGPR inoculation in reducing fertilizer input.

\section{Results}

\section{Plant-growth-promoting potential}

Among the bacterial isolates in this study, thirteen strains (N1-N13) were able to grow on nitrogen-free medium. An acetylene reduction activity (ARA) assay indicated that all thirteen isolates had nitrogenase activity, ranging from 15.14 to $156.26 \mathrm{nmol} / \mathrm{gh}$. The nitrogenase activity of isolates N2 and N9 was significantly higher than that of all other strains, and their ARA values were 113.67 and $156.26 \mathrm{nmol} / \mathrm{gh}$, respectively (Fig. 1a).

Eleven bacterial isolates were able to form a halo zone around the colonies by P solubilization. Four isolates (P2, P4, P6 and P7) could dissolve inorganic but not organic phosphate, three isolates (P8, P10 and P11) could dissolve organic but not inorganic phosphate and four isolates (P1, P3, P5 and P9) were able to dissolve both inorganic and organic phosphate (Table 1). P5 had the highest solubilization index (2.56) on PVK medium, while P11 had the highest solubilization index (4.57) on organic phosphorus dissolution medium (Fig. 1b, c and Table 1). Quantitative determination showed that the range of inorganic phosphate solubilization varied from 67.18 to $231.68 \mathrm{mg} / \mathrm{L}$, and the range of organic phosphate solubilization was between 13.67 and $40.40 \mathrm{mg} / \mathrm{L}$ (Table 1).

Fifteen bacterial isolates were able to form clear zone on Aleksandrov medium. After inoculating these 15 strains of bacteria, the soluble potassium content in the supernatant of culture medium ranged from 38.55 to $224.66 \mathrm{mg} / \mathrm{L}$. K13 strain had the strongest potassium releasing ability (Table 2). Moreover, among 39 plant growth promotion bacteria, except isolates P6, P10 and $\mathrm{K} 15$, the others could produced IAA in the presence of tryptophan. But the amount of IAA produced by them is quite different. P9 produced maximum IAA followed by P5, K7, K5, P1 and K13 (Tables 1, 2, 3). Of all the isolates, only $\mathrm{K} 14$ had strong cellulose degradation ability (Additional file 3: Table S1).

\section{Identification of bacteria}

Thirty-nine rhizosphere/endophytic bacteria with potential growth-promoting ability were isolated in vitro. Based on the sequencing results of the $16 \mathrm{~S}$ rRNA gene, these bacterial isolates belonged to 15 genera (Additional file 3: Table S1). The isolate N9 (GenBank accession number: MN658515) had the closest genetic relationship with 


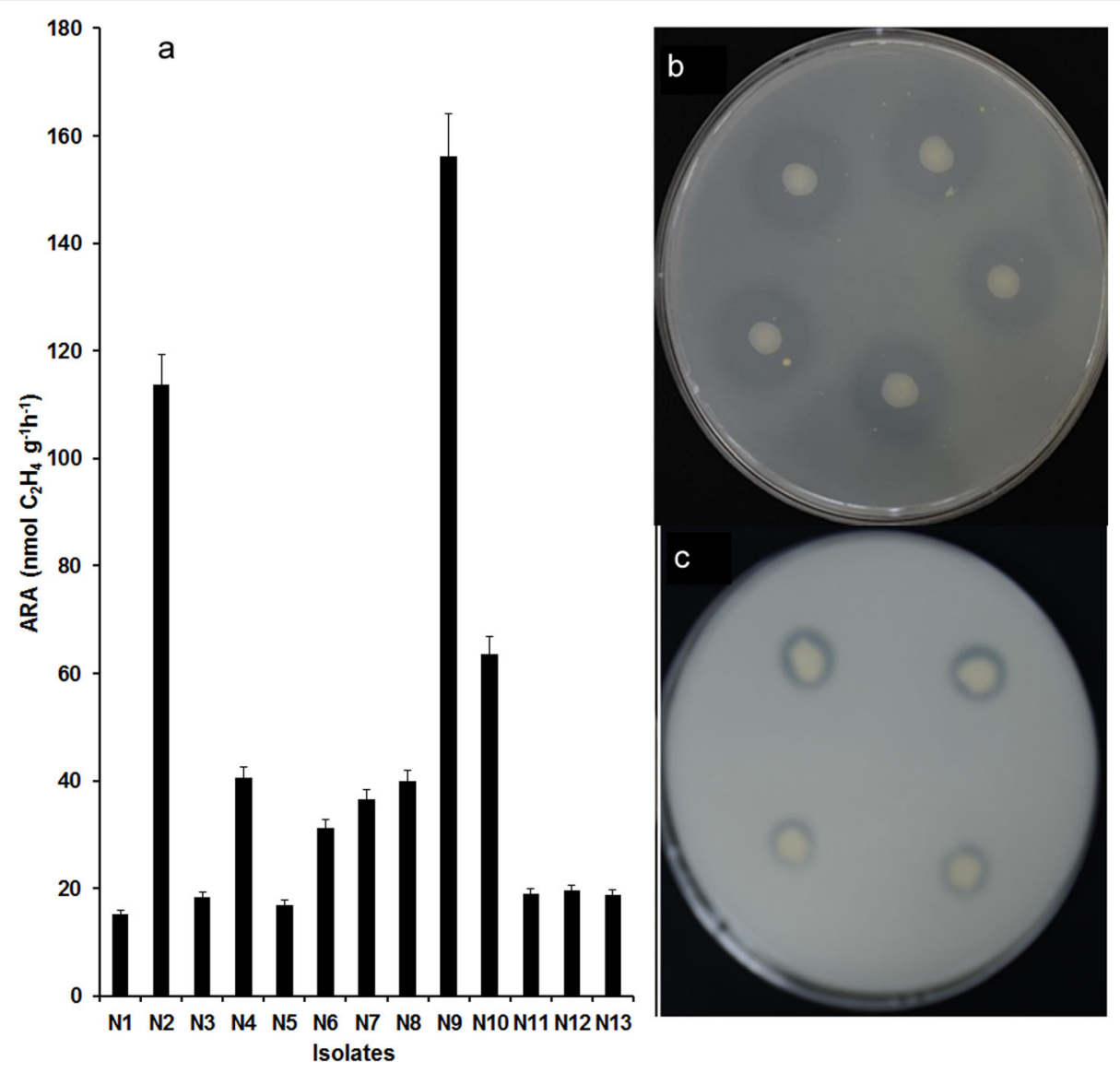

Fig. 1 Plant growth promoting potential of bacteria. a Acetylene reduction activity (ARA) of thirteen isolates. N1: Paenibacillus SP. N2, N4, N7: Azotobacter sp. N3, N5: Rheinheimera sp. N6: Agrobacterium sp. N8, N11: Pseudomonas sp. N9: Azotobacter chroococcum N10: Enterobacter sp. N12: Pantoea sp. N13: Erwinia sp. b Solubilization zone of organic phosphate c Solubilization zone of inorganic phosphate

Table 1 Phosphorus releasing ability of PGPR

\begin{tabular}{|c|c|c|c|c|c|c|c|}
\hline \multirow[t]{2}{*}{ Isolates } & \multirow[t]{2}{*}{ PGPR activities } & \multicolumn{2}{|c|}{ Inorganic phosphate } & \multicolumn{2}{|c|}{ Organic phosphate } & \multirow{2}{*}{$\begin{array}{l}\text { IAA } \\
\text { production }\end{array}$} & \multirow[t]{2}{*}{$\mathrm{pH}$} \\
\hline & & $\mathrm{SI}$ & P content(mg/L) & $\mathrm{SI}$ & P content (mg/L) & & \\
\hline P 1 (Klebsilla pneumoniae) & Organic and inorganic P solubilizing, IAA production & 1.73 & $172.28 \pm 3.15$ & + & & ++ & 5.32 \\
\hline P 2 (Klebsiella sp.) & Inorganic P solubilizing, IAA production & 1.52 & $109.25 \pm 3.15$ & - & & ++ & 5.46 \\
\hline P 3 (Enterobacter asburiae) & Organic and inorganic P solubilizing, IAA production & 2.38 & $189.19 \pm 3.91$ & + & & + & 5.13 \\
\hline P 4 (Raoultella sp.) & Inorganic P solubilizing, IAA production & 1.17 & $95.79 \pm 3.78$ & - & & + & 5.78 \\
\hline P 5 (Klebsiella variicola) & Organic and inorganic P solubilizing, IAA production & 2.56 & $231.68 \pm 3.13$ & + & & +++ & 4.96 \\
\hline P 6 (Agrobacterium sp.) & Inorganic P solubilizing & 1.32 & $67.18 \pm 3.74$ & - & & - & 6.32 \\
\hline P 7 (Rhizobium sp.) & Inorganic P solubilizing, IAA production & 1.89 & $140.21 \pm 3.81$ & - & & + & 5.96 \\
\hline P 8 (Enterobacter sp.) & Organic P solubilizing, IAA production & - & & 2.87 & $13.64 \pm 1.00$ & + & 6.78 \\
\hline P 9 (Klebsiella sp.) & Organic and inorganic P solubilizing, IAA production & + & & 2.50 & $29.93 \pm 2.47$ & +++ & 5.63 \\
\hline P 10 (Enterobacter sp.) & Organic P solubilizing & - & & 2.00 & $8.49 \pm 0.7$ & - & 6.37 \\
\hline P 11 (Comamonas SP.) & Organic P solubilizing, IAA production & - & & 4.57 & $40.40 \pm 1.90$ & + & 5.26 \\
\hline Control & & - & $1.23 \pm 0.12$ & - & $0.67 \pm 0.07$ & - & 7.02 \\
\hline
\end{tabular}


Table 2 Potassium releasing ability of PGPR

\begin{tabular}{|c|c|c|c|c|c|}
\hline Isolates & PGPR activities & $\mathrm{SI}$ & K content(mg/L) & IAA production & $\mathrm{pH}$ \\
\hline K1 (Klebsiella variicola) & $\mathrm{K}$ and $\mathrm{P}$ solubilizing, IAA production & 2.78 & $95.97 \pm 3.75$ & ++ & 4.49 \\
\hline K2 (Enterobacter sp.) & $\mathrm{K}$ and $\mathrm{P}$ solubilizing, IAA production & 2.86 & $94.64 \pm 3.00$ & + & 4.66 \\
\hline K3 (Raoultella sp.) & $\mathrm{K}$ and $\mathrm{P}$ solubilizing, IAA production & 2.79 & $83.80 \pm 2.40$ & + & 4.97 \\
\hline K4 (Klebsiella variicola) & $\mathrm{K}$ and $\mathrm{P}$ solubilizing, IAA production & 2.65 & $57.20 \pm 1.62$ & ++ & 6.11 \\
\hline K5 (Klebsiella variicola) & $\mathrm{K}$ and $\mathrm{P}$ solubilizing, IAA production & 1.39 & $64.16 \pm 2.19$ & ++ & 5.15 \\
\hline K6 (Klebsilla pneumoniae) & $\mathrm{K}$ and $\mathrm{P}$ solubilizing, IAA production & 1.57 & $38.55 \pm 2.82$ & ++ & 6.32 \\
\hline K7 (Klebsiella sp.) & $\mathrm{K}$ and $\mathrm{P}$ solubilizing, IAA production & 1.26 & $39.71 \pm 1.23$ & +++ & 6.18 \\
\hline K8 (Raoultella sp.) & $\mathrm{K}$ and $\mathrm{P}$ solubilizing, IAA production & 2.02 & $67.36 \pm 2.55$ & + & 5.29 \\
\hline K9 (Raoultella sp.) & $\mathrm{K}$ and $\mathrm{P}$ solubilizing, IAA production & 1.88 & $49.84 \pm 2.77$ & + & 5.03 \\
\hline K10 (Pseudomonas sp.) & $\mathrm{K}$ and $\mathrm{P}$ solubilizing, IAA production & 3.59 & $193.33 \pm 3.87$ & + & 4.42 \\
\hline K11 (Advenella sp.) & $\mathrm{K}$ and $\mathrm{P}$ solubilizing, IAA production & 2.97 & $117.20 \pm 3.50$ & + & 4.78 \\
\hline K12 (Agrobacterium sp.) & $\mathrm{K}$ and $\mathrm{P}$ solubilizing, IAA production & 3.02 & $154.78 \pm 3.11$ & + & 4.31 \\
\hline K13 (Rhizobium sp.) & $\mathrm{K}$ and $\mathrm{P}$ solubilizing, IAA production & 3.85 & $224.66 \pm 2.69$ & ++ & 4.03 \\
\hline K14 (Bacillus sp.) & $\mathrm{K}$ and $\mathrm{P}$ solubilizing, IAA production & 1.93 & $81.13 \pm 3.50$ & + & 5.22 \\
\hline K15 (Sphinqomonas sp.) & $\mathrm{K}$ and $\mathrm{P}$ solubilizing & 9.92 & $104.59 \pm 2.74$ & - & 5.45 \\
\hline Control & - & - & $31.96 \pm 1.60$ & - & 7.20 \\
\hline
\end{tabular}

Azotobacter chroococcum IAM12666, and its 16S rDNA sequence homology was $99.93 \%$. The isolate N8 (Accession number: MN700634) showed $97.88 \%$ similarity with Pseudomonas furukawaii KF707. The strain P9 (Accession number: NR_036794) had 100\% similarity with Klebsiella pneumoniae ATCC13884. The isolate K14 (Accession number: MN704638) had 99.34\% similarity with Bacillus niacini IFO 15566. The isolates P5 (Accession number: MN658477), K10 (Accession number: MN704376), and K13 (Accession number: MN662624) had the closest genetic relationship with Klebsiella variicola, Pseudomonas migulae, and Rhizobium larrymoorei in the phylogenetic tree based on 16S rRNA gene sequences reconstructed using MEGA (version 6), respectively (Additional file 1: Figure S1).

\section{Plant growth parameters}

To evaluate the growth-promoting effect of PGPR on wheat, 12 isolates with strong growth-promoting ability and one growth-promoting bacterium "176" (Agrobacterium tumefaciens CCNWGS0286) preserved in our laboratory were inoculated into plant roots. However, there was no difference in wheat plant height among 13 singleinoculated treatments and the non-inoculated treatment. Therefore, the isolates with nitrogen fixation, inorganic/organic phosphate and potassium-releasing ability and strain 176 were combined. Ten out of thirty-six PGPRs combinations significantly increased the plant height of wheat. Meanwhile, eight combinations enhanced the dry weight of wheat (Fig. 2). K14 (Bacillus sp.) +176 (Agrobacterium tumefaciens) + P9 (Klebsiella pneumoniae) + N8 (Pseudomonas sp.) + P5 (Klebsiella variicola) and K14 (Bacillus sp.) +176 (Agrobacterium tumefaciens) + P9 (Klebsiella pneumoniae $)+\mathrm{N} 9 \quad$ (Azotobacter chroococcum $)+\mathrm{K} 10$ (Pseudomonas sp.) maximized the dry weight and height of wheat. Shoot height and plant dry mass were increased by 18.59 and $105 \%(P<0.05)$, respectively, in plants inoculated with $\mathrm{K} 14+176+\mathrm{P} 9+\mathrm{N} 8+\mathrm{P} 5$ and $\mathrm{K} 14+176+\mathrm{P} 9+\mathrm{N} 9+$ K10 group compared to plants without inoculum (Fig. 2 and Additional file 3: Table S2).

Table 3 PGPR activities of nitrogen fixing bacteria

\begin{tabular}{|c|c|c|c|c|c|}
\hline Isolates & PGPR activities & IAA & Isolates & PGPR activities & IAA \\
\hline N1 (Paenibacillus SP.) & Nitrogen fixation, IAA production & + & N8 (Pseudomonas sp.) & Nitrogen fixation, IAA production & + \\
\hline N2 (Azotobacter sp.) & Nitrogen fixation, IAA production & + & N9 (Azotobacter chroococcum) & Nitrogen fixation, IAA production & + \\
\hline N3 (Rheinheimera sp.) & Nitrogen fixation, IAA production & + & N10 (Enterobacter sp.) & Nitrogen fixation, IAA production & ++ \\
\hline N4 (Azotobacter sp.) & Nitrogen fixation, IAA production & + & N11 (Pseudomonas sp.) & Nitrogen fixation, IAA production & + \\
\hline N5 (Rheinheimera sp.) & Nitrogen fixation, IAA production & + & N12 (Pantoea sp.) & Nitrogen fixation, IAA production & ++ \\
\hline N6 (Agrobacterium sp.) & Nitrogen fixation, IAA production & + & N13 (Erwinia sp.) & Nitrogen fixation, IAA production & + \\
\hline N7 (Azotobacter sp.) & Nitrogen fixation, IAA production & + & & & \\
\hline
\end{tabular}



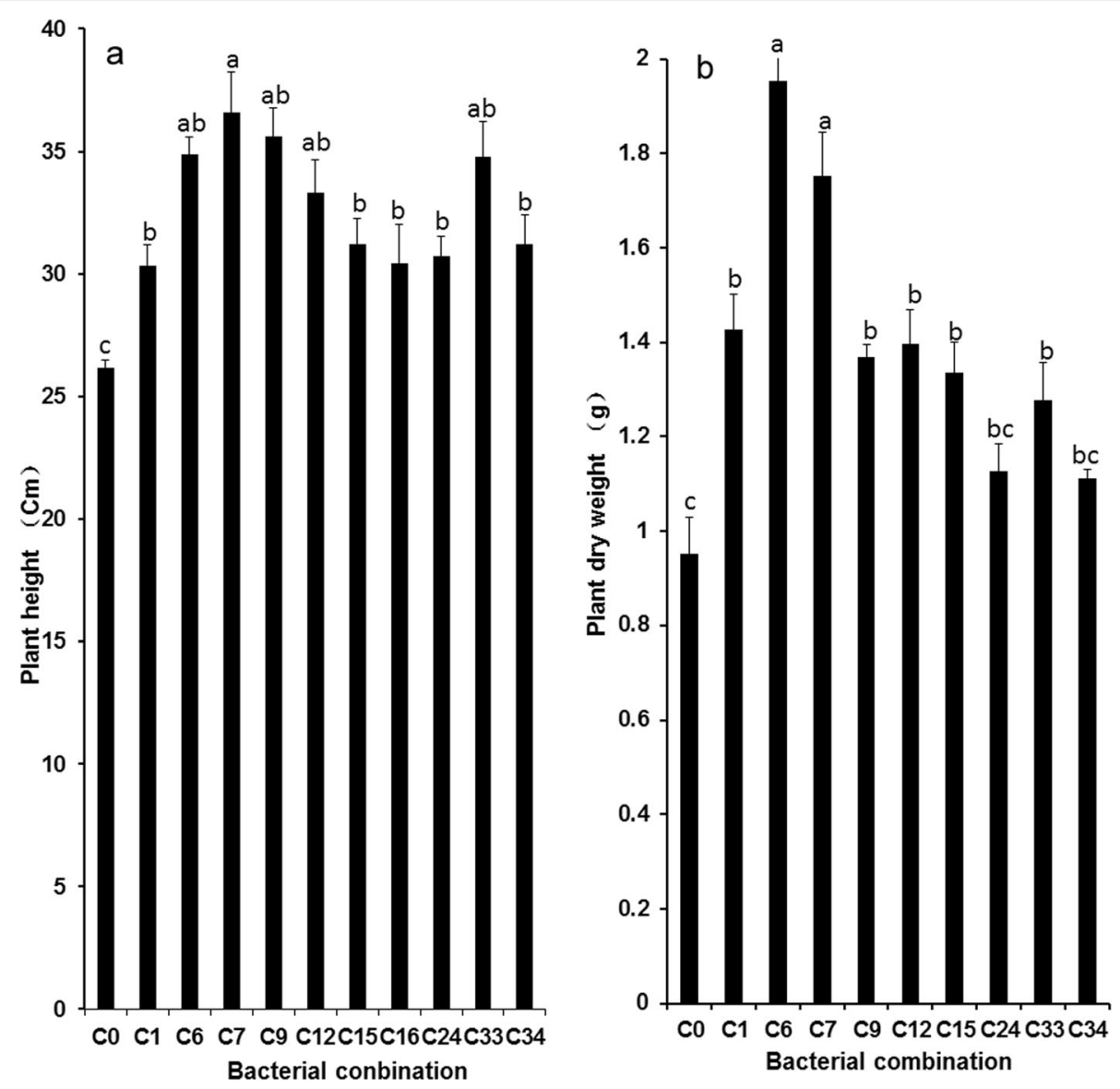

Fig. 2 The effect of bacterial combination on $\mathbf{a}$ plant height and $\mathbf{b}$ plant dry biomass of wheat. Values are means $\pm S E$. abcd letters on the bars denote differences on the basis of a t-test $(p<0.05)$. C0: Control C1: K14 + 176 + P9 + N8 + K10 C6: K14 + 176 + P9 + N8 + P5 C7: K14 + 176 + P9 + $\mathrm{N} 9+\mathrm{K} 10 \mathrm{C} 9: \mathrm{K} 14+176+\mathrm{P} 9+\mathrm{N} 9+\mathrm{K} 13 \mathrm{C12}: \mathrm{K} 14+176+\mathrm{P} 9+\mathrm{N} 9+\mathrm{P} 5 \mathrm{C} 15: \mathrm{K} 14+176+\mathrm{P} 9+\mathrm{N} 10+\mathrm{K} 13 \mathrm{C} 16: \mathrm{K} 14+176+\mathrm{P} 9+\mathrm{N} 10+\mathrm{P} 1 \mathrm{C} 24: \mathrm{K} 14+$ $176+\mathrm{P} 11+\mathrm{N} 8+\mathrm{P} 5 \mathrm{C} 33: \mathrm{K} 14+176+\mathrm{P} 11+\mathrm{N} 10+\mathrm{K} 13 \mathrm{C} 34: \mathrm{K} 14+176+\mathrm{P} 11+\mathrm{N} 10+\mathrm{P} 1$

\section{Determination of nutrients in rhizosphere soil}

Ten bacterial combinations with good growth-promoting effects were inoculated into wheat roots, and the available nitrogen, phosphorus and potassium contents in the soil were determined after 80 days of plant growth. Compared with the control, the alkali-hydrolysed nitrogen, available phosphorus and available potassium in all inoculated soil were increased to varying degrees. Among the combinations K14 (Bacillus sp.) +176 (Agrobacterium tumefaciens) + P9 (Klebsiella pneumoniae) + N8 (Pseudomonas sp.) + P5 (Klebsiella variicola) had the most notable effect on soil nutrient improvement. The alkali-hydrolysed nitrogen, available phosphorus and available potassium increased by 49.46, 99.51 and 19.38\%, respectively (Table 4).

\section{Determination of $\mathrm{N} / \mathrm{P} / \mathrm{K}$ content in wheat}

In order to verify whether inoculation treatment can promote nutrient uptake by plants, the contents of nitrogen, phosphorus and potassium in wheat were determined. As shown in Fig. 3, significant increases in plant
$\mathrm{N} / \mathrm{P} / \mathrm{K}$ uptake were observed when the soil was inoculated with different combinations of bacteria compared with the non-inoculated control. For wheat inoculated with different bacterial combinations, the plant $\mathrm{N}$ content increased from 40.7 to $97.7 \%(P<0.05)$. Additionally, the $\mathrm{P}$ content of wheat increased from 41.2 to $96.4 \%$, and the K content increased from 2.3 to $42.1 \%$.

\section{Effect of reducing fertilizer application}

Since the combination of $\mathrm{K} 14+176+\mathrm{P} 9+\mathrm{N} 8+\mathrm{P} 5$ could activate nutrients in soil and promote the utilization of nitrogen, phosphorus and potassium by plants, we validated whether this PGPR combination inoculation could reduce fertilizer doses. The results are shown in Figs. 4 and 5, Compared with a $100 \%$ fertilizer dose, the reduction of fertilizer application by 25,50 and $100 \%$ significantly inhibited plant growth. When no fertilizer was added to the soil, the combined PGPR inoculation significantly increased plant height, tiller counts, fresh weight and dry weight but still did not perform as well 
Table 4 The effect of bacterial combination on available N/P/K content in soil

\begin{tabular}{|c|c|c|c|c|}
\hline & Combination & Alkali-hydrolyzed nitrogen (mg/kg soil) & Available P (mg/kg soil) & Available K (mg/kg soil) \\
\hline $\mathrm{CO}$ & Control & $12.13 \pm 0.2^{c}$ & $7.48 \pm 0.8^{c}$ & $87.47 \pm 2.1^{d}$ \\
\hline C1 & $\mathrm{K} 14+176+\mathrm{P} 9+\mathrm{N} 8+\mathrm{K} 10$ & $18.71 \pm 1.1^{b}$ & $11.69 \pm 1.4^{\mathrm{b}}$ & $95.79 \pm 2.9^{\mathrm{bcd}}$ \\
\hline C6 & $\mathrm{K} 14+176+\mathrm{P} 9+\mathrm{N} 8+\mathrm{P} 5$ & $21.98 \pm 1.4^{\mathrm{a}}$ & $14.92 \pm 1.1^{\mathrm{a}}$ & $104.42 \pm 2.8^{\mathrm{a}}$ \\
\hline C7 & $\mathrm{K} 14+176+\mathrm{P} 9+\mathrm{N} 9+\mathrm{K} 10$ & $19.28 \pm 1.5^{b}$ & $13.09 \pm 0.4^{\mathrm{ab}}$ & $98.24 \pm 2.8^{\mathrm{abc}}$ \\
\hline C9 & $\mathrm{K} 14+176+\mathrm{P} 9+\mathrm{N} 9+\mathrm{K} 13$ & $19.55 \pm 0.9^{b}$ & $14.19 \pm 1.1^{\mathrm{ab}}$ & $100.51 \pm 1.0^{\mathrm{ab}}$ \\
\hline $\mathrm{C} 12$ & $\mathrm{~K} 14+176+\mathrm{P} 9+\mathrm{N} 9+\mathrm{P} 5$ & $18.71 \pm 0.8^{b}$ & $11.49 \pm 1.0^{\mathrm{b}}$ & $90.38 \pm 6.3^{\mathrm{cd}}$ \\
\hline C15 & $\mathrm{K} 14+176+\mathrm{P} 9+\mathrm{N} 10+\mathrm{K} 13$ & $18.01 \pm 1.4^{b}$ & $12.00 \pm 1.2^{\mathrm{ab}}$ & $93.86 \pm 4.4^{\mathrm{bcd}}$ \\
\hline C16 & $\mathrm{K} 14+176+\mathrm{P} 9+\mathrm{N} 10+\mathrm{P} 1$ & $18.13 \pm 0.9^{b}$ & $12.63 \pm 1.1^{\mathrm{ab}}$ & $89.20 \pm 5.2^{c d}$ \\
\hline C24 & $\mathrm{K} 14+176+\mathrm{P} 11+\mathrm{N} 8+\mathrm{P} 5$ & $14.51 \pm 1.6^{c}$ & $11.47 \pm 1.2^{b}$ & $91.33 \pm 1.5^{\mathrm{bcd}}$ \\
\hline C33 & $\mathrm{K} 14+176+\mathrm{P} 11+\mathrm{N} 10+\mathrm{K} 13$ & $14.76 \pm 0.6^{c}$ & $11.18 \pm 0.9^{b}$ & $86.51 \pm 2.5^{d}$ \\
\hline C34 & $\mathrm{K} 14+176+\mathrm{P} 11+\mathrm{N} 10+\mathrm{P} 1$ & $14.51 \pm 1.6^{c}$ & $11.72 \pm 0.9^{b}$ & $93.27 \pm 4.5^{\mathrm{bcd}}$ \\
\hline
\end{tabular}

Values are means \pm SE. abcd letters on the bars denote differences on the basis of a t-test $(p<0.05)$

as $100 \%$ fertilizer application without PGPR. However, there was no difference in plant height, fresh weight, tiller counts, or $\mathrm{N} / \mathrm{P} / \mathrm{K}$ content between PGPR combination $+75 \%$ fertilizer and 100\% fertilizer without PGPR (Figs. 4 and 5). Compared with 100\% fertilizer, PGPR combination $+75 \%$ fertilizer did not reduce available nitrogen, phosphorus or potassium in the soil (Additional file 2: Figure S2).
In sum, these results showed that the combination of $\mathrm{K} 14+176+\mathrm{P} 9+\mathrm{N} 8+\mathrm{P} 5$ could promote nitrogen, phosphorus and potassium accumulation in wheat, and reduce the application of chemical fertilizer by $25 \%$.

\section{Discussion}

There is a very complex system of interactions among microorganisms and between microorganisms and plants in

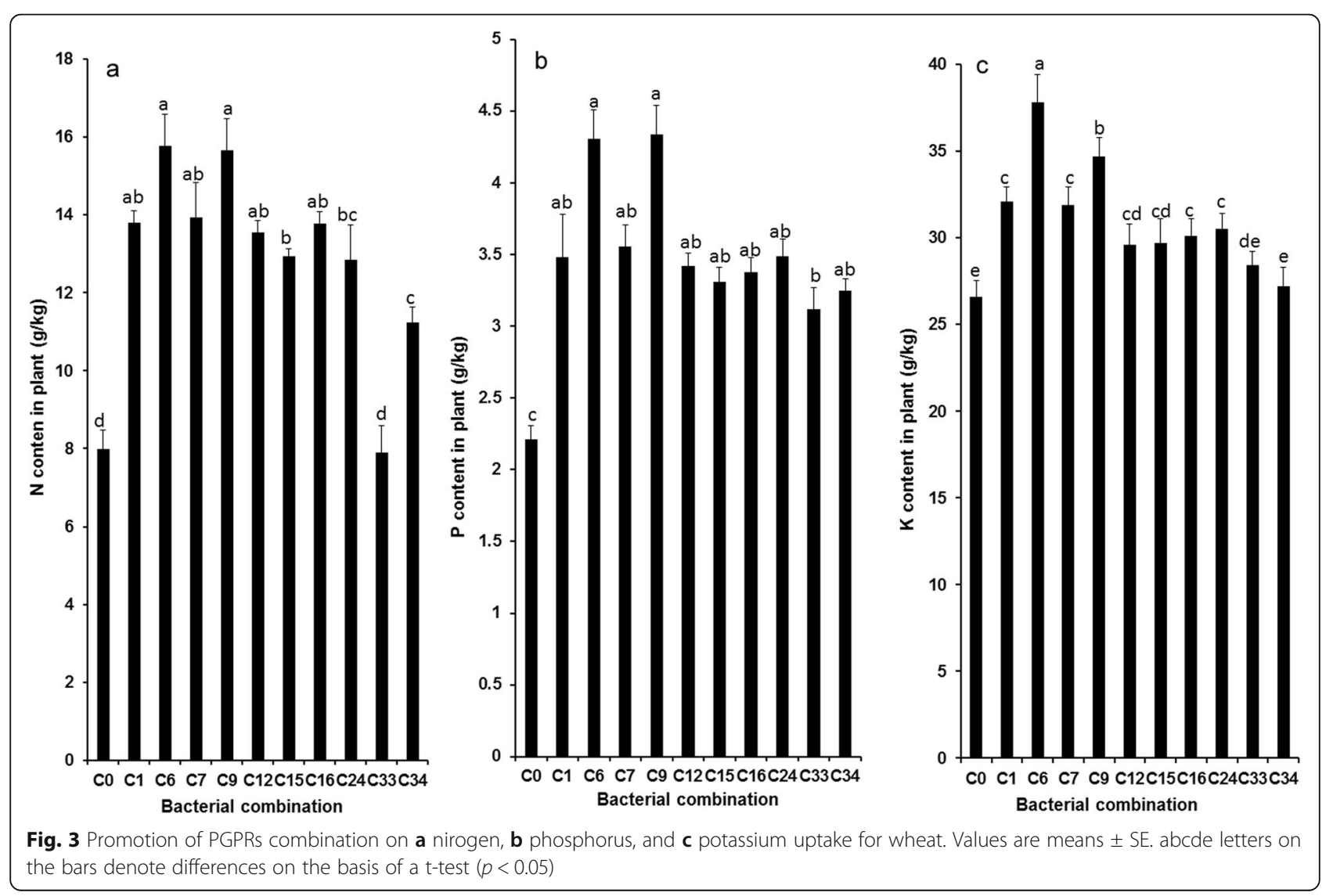



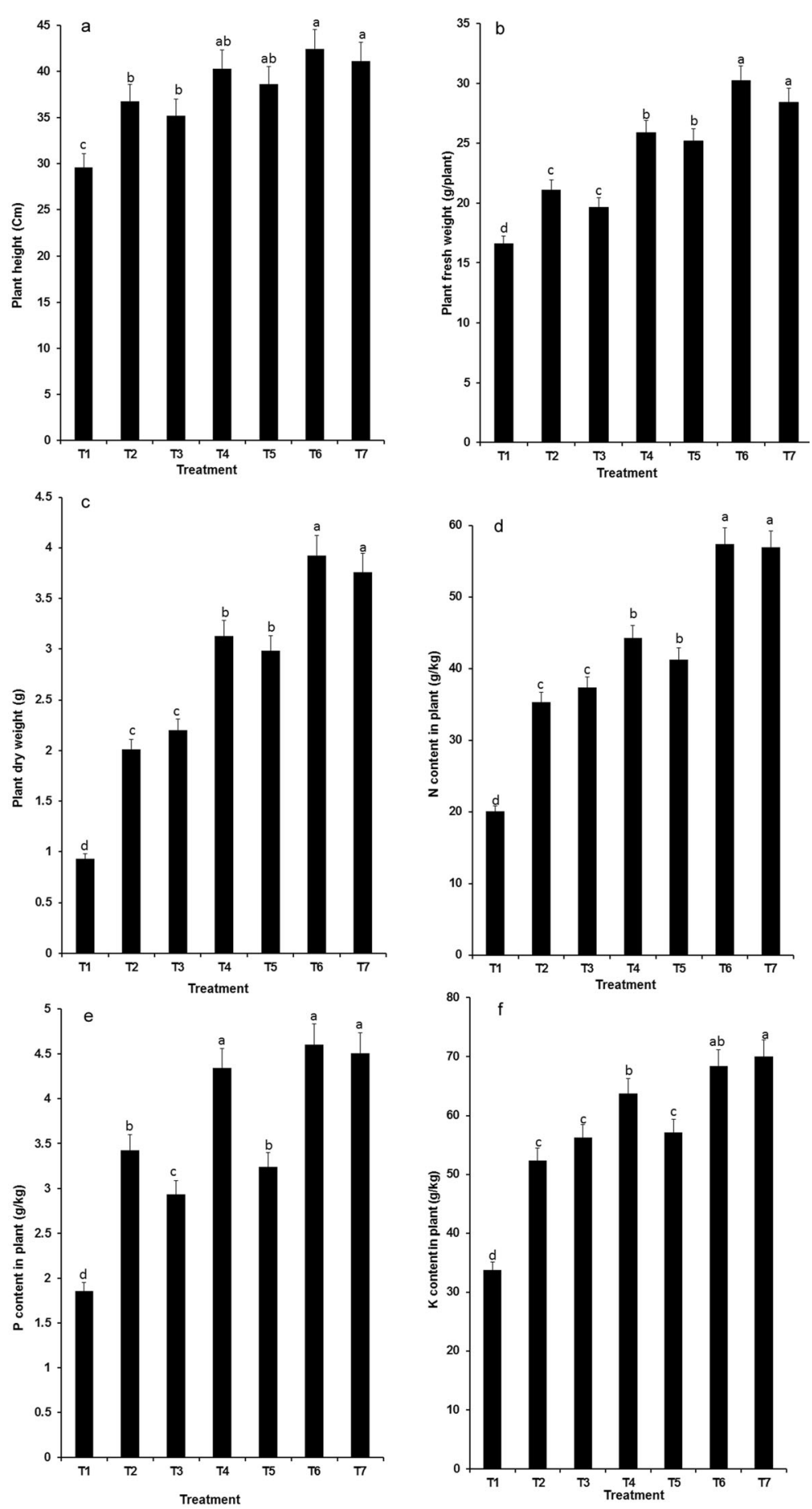

Fig. 4 The effect of bacterial combination $\mathrm{K} 14+176+\mathrm{P} 9+\mathrm{N} 8+\mathrm{P} 5$ on a plant height, $\mathbf{b}$ plant fresh weight, $\mathbf{c}$ plant dry weight, $\mathbf{d} \mathrm{N}$ content in plant, e $\mathrm{P}$ content in plant, and $\mathbf{f} \mathrm{K}$ content in plant of wheat. T1: without fertilizer, T2: PGPR combination 6, T4: 50\% fertilizer + PGPR combination 6, T6: 75\% fertilizer + PGPR combination 6, T7: 100\% fertilizer. Values are means \pm SE. abcd letters on the bars denote differences on the basis of a t-test $(p<0.05)$

soil. Under certain conditions, plants recruit beneficial microorganisms to colonize the rhizosphere or root tissue by secreting metabolites to the soil [22]. These microorganisms can improve plant adaption to biotic and abiotic stresses [23], inhibit the growth of plant pathogens by producing antimicrobial compounds or competing with pathogens for nutrients [24], and activate nutrients in soil [25]. The nitrogen-fixing, and $\mathrm{P} / \mathrm{K}$-releasing potential of bacteria 

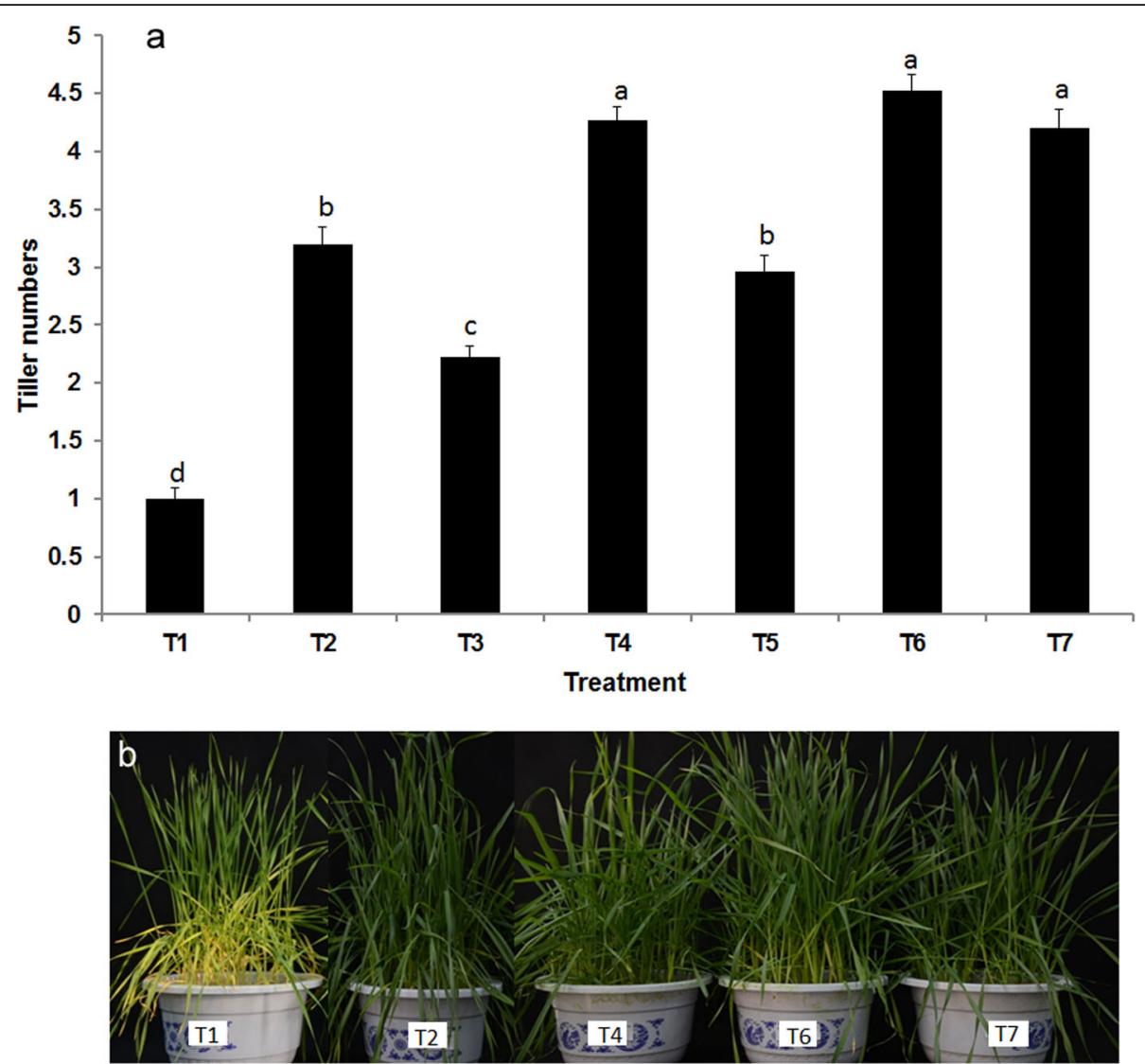

Fig. 5 a The effect of bacterial combination $\mathrm{K} 14+176+\mathrm{P} 9+\mathrm{N} 8+\mathrm{P} 5$ and fertilizer application on tiller number of potted wheat. Values are means \pm SE. abcd letters on the bars denote differences on the basis of a t-test $(p<0.05)$. $\mathbf{b}$ Phenotype of wheat under different fertilization treatments. T1: without fertilizer, T2: PGPR combination 6, T3: 50\% fertilizer, T4: 50\% fertilizer + PGPR combination 6, T5: 75\% fertilizer, T6: 75\% fertilizer + PGPR combination 6, T7: 100\% fertilizer

isolated from the rhizosphere and root of wheat was analysed. Finally, thirty-nine bacterial strains with plantgrowth-promoting ability were isolated using different screening media. The $16 \mathrm{~S}$ rRNA sequence analysis revealed that these bacteria belong to 15 genera (Additional file 3: Table S1). The nitrogenase activity of Azotobacter was much higher than that of other bacteria (Fig. 1), and strain N9, with the highest nitrogenase activity, showed 99.93\% similarity with $A$. chroococcum IAM12666. The results presented in this paper are in agreement with previous works. A. chroococcum has been isolated from the rhizosphere or roots of many plants such as litchi, rice, and faba bean [26, 27]. The results of a study by Rodelas et al. [27] showed that the acetylene reduction activity of Azotobacter sp. was between 9.7 and $257.7 \mathrm{nmol} \mathrm{C}_{2} \mathrm{H}_{4} \mathrm{~h}^{-1}$ vial $^{-1}$, while $A$. chroococcum isolates had a high capacity for acetylene reduction.

In addition to nitrogen, phosphorus and potassium are the other two essential plant growth-limiting nutrients. Although potassium and phosphorus are abundant elements in soil, they are mostly bound to other minerals. Approximately $95-99 \%$ of phosphorous and potassium are present in insoluble form and therefore unavailable to plants. Some soil microorganisms can dissolve otherwise insoluble phosphate and potassium. Several studies have shown that different bacterial genera, such as Pseudomonas, Bacillus, Rhizobium, Agrobacterium, Klebsilla, and Erwinia, have the potential to solubilize and release phosphorus/potassium from soil [28]. In the present work, 11 phosphate-solubilizing bacteria and 15 potassium-solubilizing bacteria were isolated from the rhizosphere and roots of wheat. These microbial isolates showed potassium solubilization index from 1.26 to 3.85 or phosphate solubilization indices from 1.17 to 4.57 on PVK or Aleksandrov medium (Tables 1 and 2). These bacterial isolates comprise 9 Klebsilla, 4 Enterobacter, 4 Raoultella, 2 Rhizobium, 2 Agrobacterium, 1 Bacillus, 1 Advenella, 1 Microbacterium, 1 Comamonas, and 1 Pseudomonas isolate (Additional file 3: Table S1), this is consistent with previous studies. Maliha et al. [29] showed that bacteria released organic acids and decreased the $\mathrm{pH}$ of the rhizosphere, which led to the dissolution of the mineral phosphate. The selected bacterial strains were grown using a broth culture method, and the phosphorus/potassium content and $\mathrm{pH}$ of the 
culture medium were analysed quantitatively. Compared with the non-inoculated control, the inoculated treatment showed significantly increased phosphorus/potassium content in broth and reduced median $\mathrm{pH}$. Meanwhile, the more $\mathrm{pH}$ decreased, the larger the solubilization index and the more phosphorus/potassium content in broth was observed. Potassium-solubilizing bacteria can also dissolve tricalcium phosphate in medium (Tables 1 and 2 and Additional file 3: Table S1). The results indicated that the bacteria we isolated dissolve insoluble phosphate/potassium mainly by producing organic acids.

In addition to focusing on biological nitrogen fixation and phosphate/potassium solubilization, we investigated the IAA-producing potential of in these bacterial isolates. The results showed that most of the isolates could synthesize IAA, but their production rates were quite different. This variation is due to the different synthetic pathways, key genes and regulatory strategies of different bacteria [30]. Bacteria isolated from the rhizosphere of soybean and rice have been shown to produce 10.54 to $84.72 \mathrm{mg} / \mathrm{kg}$ IAA [31, 32]. The strain P9 (P-solubilizing bacteria) showed the highest IAA production, followed by the strains P5 and K7 (Tables 1, 2, and 3). The measured production of IAA was higher in this work than in previous reports. This suggested that these isolates could serve as efficient biofertilizer candidates for activating phosphorus/potassium and simultaneously promoting crop growth.

It is important to consider that the growth-promoting performance of bacteria will be influenced by biotic and abiotic factors in soil. We combined bacteria with different functions and performed experiments in a greenhouse. The results of pot-based experiments showed that ten combinations significantly increased the available phosphorus/potassium and alkali hydrolysed nitrogen in the soil, and the plant height, dry biomass, and $\mathrm{N} / \mathrm{P} / \mathrm{K}$ content of wheat also increased after inoculation with these ten bacterial combinations. Among them, the combination $\mathrm{K} 14+176+\mathrm{P} 9+\mathrm{N} 8+\mathrm{P} 5$ had the best growth-promoting effect (Fig. 4). In combination K14+ $176+\mathrm{P} 9+\mathrm{N} 8+\mathrm{P} 5$ with better growth promoting effect, the isolates P5, N8, P9 and K14 had the closest genetic relationship with Klebsiella Klebsiella variicola, Pseudomonas furukawaii, Klebsiella pneumoniae and Bacillus niacini, respectively. Through analysis the genome of the strain 176, two possible pathways for IAA synthesizing have been found. The genes ATCR1_06021 and ATCR1_10873, ATCR1_02965, ATCR1_10883, ATCR1_ 10878, ATCR1_02970, and ATCR1_23021 may be inovolve in the synthesis of tryptophan. Genes ATCR1 17572 (encoding amine oxidase) and ATCR1_06371 (indole-3-acetaldehyde dehydrogenase) involved in TAM (tryptamine) pathway, while ATCR1_17003 (nitrilase) and ATCR1_07569 (monooxygenase) involved in IAM (indole-3-acetamide) pathway. Previous study has confirmed that excessive production of IAA by strain 176 is an important reason for plant growth-promoting [33]. In $K$. variicola DX120E, the genome contains nif gene cluster, indole-3-pyruvate decarboxylase, and siderophore enterobactin synthesis genes (ent $\mathrm{ABCDEF)} \mathrm{which} \mathrm{con-}$ tribute to $\mathrm{N}_{2}$ fixation, indole-3-acetic acid production, siderophore production, and phosphate solubilization. Besides ferric iron uptake transcriptional regulator gene fur and indole-3-glycerol phosphate synthase gene $\operatorname{tr} p \mathrm{C}$, there are 10 inorganic phosphorus dissolving genes

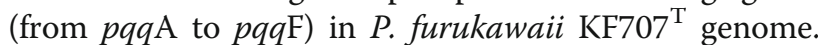
This strain also encodes antioxidant enzymes, such as superoxide dismutase and catalase, which have the ability to remove free radicals under stresses. The genome of B. niacini NBRC $15566^{\mathrm{T}}$ contains 13 genes involved in iron transport and ferric uptake regulation, and there are $\operatorname{trpC}$ gene (encoding indole-3-glycerol phosphate synthase) and 4 phospholipase genes. Thus these growth-promoting genes may be closely related to the increase of available $\mathrm{N}, \mathrm{P}, \mathrm{K}$ in soil and plant growth (Fig. 1, Tables 1, 2, and 3). Thus we speculated that the improvement of plant growth can be attributed to nitrogen fixation and phosphate/potassium solubilization by PGPR, which provides great deal of nutrition for plant development [34]. Furthermore, IAA can be produced by inoculated PGPR. IAA is involved in cell division, root growth, and stem elongation, increasing the surface area of roots such that plants con obtain additional water and nutrients [35]. A large number of studies have focused on the role of PGPR in promoting crop growth $[36,37]$. However, bacteria are not a complete substitute for fertilizers. In the present study, the potential of PGPR in reducing fertilizer application was also investigated. The plant dry weight, $\mathrm{N} / \mathrm{P} / \mathrm{K}$ content and tiller counts were not affected by a $25 \%$ decrease in fertilizer after inoculation with the combination $\mathrm{K} 14+176+\mathrm{P} 9+$ $\mathrm{N} 8+\mathrm{P} 5$. In conclusion, these PGPR can be used as biofertilizer and have broad application prospects in sustainable agricultural development.

\section{Conclusions}

These results clearly showed that $\mathrm{N}_{2}$-fixing, P-solubilizing, $\mathrm{K}$-solubilizing and IAA-producing bacteria can significantly increase available nitrogen, phosphorus and potassium in soil. A combination of growth-promoting bacteria with different functions effectively improved $N / P / K$ uptake and plant growth in wheat. These bacterial isolates allow the use of lower chemical fertilizer doses than traditional fertilization strategies and have greater application potential in the field. However, future studies are needed to investigate other conditions, locations and crops to verify the reliability of the present study. 


\section{Methods}

\section{Isolation of bacteria}

Samples of wheat were obtained from fields in which wheat had been cultivated continuously for more than 10 years in Yangling, China. Plants with rhizosphere soil were placed in sterile plastic bags and brought back to the laboratory. For isolation of rhizosphere bacteria, $1 \mathrm{~g}$ of rhizospheric soil was taken in $10 \mathrm{ml}$ of sterile water and shaked for $10 \mathrm{~min}$. $1 \mathrm{~g}$ of fresh wheat roots were washed under running tap water and surface sterilized with $4 \% \mathrm{NaOCl}$ for $1 \mathrm{~min}$. After washing six times with sterilized distilled water, the roots were ground with a sterilized mortar and pestle. These two suspension were then serially diluted to $10^{-8}$ grades, $0.1 \mathrm{ml}$ of each dilution of $1 \times 10^{-6}, 1 \times 10^{-7}$, and $1 \times 10^{-8}$ dilution was spreaded on TY agar plates (Tryptone $5 \mathrm{~g}$, Yeast extract $3 \mathrm{~g}, \mathrm{CaCl}_{2} 0.2 \mathrm{~g}$, Agar $15 \mathrm{~g}$, distilled water $1000 \mathrm{ml}$ ). The plates were incubated at $28 \mathrm{C}$ for 5 days. Isolates showing different colony characters were selected, purified and stored in liquid TY medium containing 20\% glycerol at $-80^{\circ} \mathrm{C}$.

\section{Screening for plant-growth-promoting traits Nitrogen fixation}

The purified colonies were streaked on Ashby agar (sucrose $10 \mathrm{~g}, \mathrm{KH}_{2} \mathrm{PO}_{4} 0.2 \mathrm{~g}, \mathrm{NaCl} 0.2 \mathrm{~g}, \mathrm{MgSO}_{4} 0.2 \mathrm{~g}$, $\mathrm{K}_{2} \mathrm{SO}_{4} 0.2 \mathrm{~g}, \mathrm{CaCO}_{3} 5 \mathrm{~g}$, agar $15 \mathrm{~g}$, distilled water 1000 $\mathrm{ml}$ ) and incubated at $30^{\circ} \mathrm{C}$ for 7 days. The sticky colonies were inoculated into Ashby solid medium vials and incubated at $28{ }^{\circ} \mathrm{C}$ for $24 \mathrm{~h}$. Five hundred microliters of air was replaced with $500 \mu \mathrm{L}$ of acetylene, and the vials were incubated at $28^{\circ} \mathrm{C}$ for $24 \mathrm{~h}$. Then $600 \mu \mathrm{L}$ of gas was extracted from vials and the ethylene content was analysed with a gas chromatograph (Shimadzu GC17A, Japan) equipped with an $\mathrm{H}$-flame ionization detector using methods described by Hardy et al. [38]. At the same time, the bacteria on surface of the solid medium in the vials were washed down, dried and weighed. The acetylene reducing activity (ARA) was calculated as follows:

$$
A R A=\frac{\text { Ethylene production }(\text { nmol })}{\text { Bacteria weight }(g) \times \text { Reaction tiem }(h)}
$$

\section{Solubilization of phosphate and potassium}

Each bacterial colony was inoculated on PVK medium [39], organic phosphorus dissolution medium [glucose $10 \mathrm{~g},\left(\mathrm{NH}_{4}\right)_{2} \mathrm{SO}_{4} 0.5 \mathrm{~g}, \mathrm{NaCl} 0.3 \mathrm{~g}, \mathrm{KCl} 0.3 \mathrm{~g}, \mathrm{FeSO}_{4} 0.03$ g, $\mathrm{MnSO}_{4} 0.03 \mathrm{~g}, \mathrm{CaCO}_{3} 5 \mathrm{~g}$, lecithin $0.2 \mathrm{~g}$ (Aladdin Biochemical Technology Co., Ltd., China), agar $15 \mathrm{~g}$ and distilled water $1000 \mathrm{ml}$, and Aleksandrov medium [glucose $5 \mathrm{~g}, \mathrm{MgSO}_{4} 0.5 \mathrm{~g}, \mathrm{CaCO}_{3} 0.1 \mathrm{~g}, \mathrm{FeCl}_{3} 0.006 \mathrm{~g}$, $\mathrm{Ca}_{3} \mathrm{PO}_{4} 2.0 \mathrm{~g}$ (Kemiou Chemical Reagent Co., Ltd.,
China), Potassium aluminium silicate $3.0 \mathrm{~g}$ (Daiquan Fine Chemical \& Technology Co., Ltd., China), agar $15 \mathrm{~g}$ and distilled water $1000 \mathrm{ml}$ ], respectively. The plates were incubated at $28{ }^{\circ} \mathrm{C}$ for 7 days and observed for the clear zone around the colonies. The solubilization index (SI) was calculated as follows:

\section{$S I=$ Diameter of zone of clearance/Diameter of colony}

Then, the phosphate/potassium-soluble strains were inoculated into the corresponding liquid medium and incubated at $28^{\circ} \mathrm{C}, 180 \mathrm{rpm}$ for 5 days. The $\mathrm{pH}$ value of solution was measured by PHS-3C $\mathrm{pH}$ meter (INESA Scientific Instrument Co., Ltd, China).The P concentration in the solution was determined using the molybdovanadate method [40]. The $K$ concentration in the solution was estimated using atomic absorption spectrometry [41].

\section{Production of IAA}

Bacterial isolates were grown in TY supplemented with tryptophan $(500 \mathrm{mg} / \mathrm{L})$ and incubated at $28^{\circ} \mathrm{C}$ for $48 \mathrm{~h}$ on a rotary shaker. Cultures were centrifuged at $12,000 \mathrm{~g}$ for $10 \mathrm{~min}$. A $1 \mathrm{ml}$ volume of supernatant was placed into an EP tube, and an equal volume of Salkowski reagent was added and the optical density of $530 \mathrm{~nm}$ (OD530) of solution was measured after $30 \mathrm{~min}$ of reaction in dark. The different concentration of IAA $(0,20$, $40,60,80,100,120,140,160$ and $180 \mathrm{mg} / \mathrm{L})$ was prepared. OD530 of each concentration IAA solution was determined and the standard curve was drawn. Then the IAA content of bacterial culture medium was calculated based on standard curve.

\section{Determination of cellulose degradation}

Each bacterial colone was inoculated on cellulolytic culture medium (sodium carboxymethyl cellulose $5 \mathrm{~g}$, yeast extract $2 \mathrm{~g}, \mathrm{KH}_{2} \mathrm{PO}_{4}, 0.5 \mathrm{~g} \mathrm{MgSO}_{4} 0.5 \mathrm{~g}$, agar $15 \mathrm{~g}$ and distilled water $1000 \mathrm{ml}$ ) and incubated at $28{ }^{\circ} \mathrm{C}$ for 3 days. Then, colonies were stained with $1 \mathrm{mg} / \mathrm{mL}$ Congo red dye for $15 \mathrm{~min}$ and decolorized with $1 \mathrm{~mol} / \mathrm{L} \mathrm{NaCl}$ for $30 \mathrm{~min}$. Colonies with clear zones indicated that the bacteria had the ability to degrade cellulose.

\section{Molecular characterization of the PGPR strains}

The total genomic DNA of 39 bacterial strains was extracted according to the method of Wilson \& Carson [42]. The 16S rRNA region was amplified using forward primer 27F (5-AGAGTTTGATCC TGGCTCAG-3) and reverse primer 1492R (5-TACGGCTACCTTGTTACG ACTT-3). The resulting products were confirmed on a $1 \%$ agarose gel, and then the correct PCR products were sequenced Sangon Biotech (Shanghai) Co., Ltd., China. 
The obtained gene sequences were analysed using the BLASTN program.

\section{Plant growth promotion}

The top layer of the soil, $0-20 \mathrm{~cm}$ deep, was collected from abandoned farmland, air dried, passed through a 2 $\mathrm{mm}$ sieve and thoroughly homogenized. Pots measuring $23 \mathrm{~cm}$ in diameter and $17 \mathrm{~cm}$ in height were filled with $3 \mathrm{~kg}$ of soil each. Seeds of the wheat (Triticum aestivum L.) variety Xiaoyan 22 were purchased from Yangling Jinnuo seed Co., Ltd. in China. The seeds were surface sterilized with a $3 \%$ sodium hypochlorite solution for 10 mins, followed by six rinses with deionized distilled water. Sterilized wheat seeds were planted in the pots. After the wheat seedlings had been growing for 1 week, 10 plants were retained in each pot, and $10 \mathrm{~mL}$ of a combination of 5 PGPRs (contains $2 \mathrm{~mL}$ each PGPR with $10^{8}$ colony formation unit) was inoculated into plant roots. K14 has a strong ability to degrade cellulose, 176 is a known growth-promoting bacterium preserved in our laboratory; all the PGPR combinations contain these two bacterial strains. The other three strains were selected from phosphorus-solubilizing (P1, P5, P9 and P11), nitrogen-fixing (N8, N9 and N10) and potassiumsolubilizing bacteria (K10 and K13). This results in 36 inoculation combinations. Uninoculated pots were included as negative controls. All pots were placed in a greenhouse with a $16 / 8 \mathrm{~h}$ photoperiod (light/dark) and at $25 \pm 1{ }^{\circ} \mathrm{C}$ for 80 days. The plants were watered with $250 \mathrm{~mL}$ water every 3 days during the experiment. The plants were harvested after 80 days, and the fresh weight, dry weight, shoot length, and $\mathrm{N} / \mathrm{P} / \mathrm{K}$ content of the plants and the available $\mathrm{N} / \mathrm{P} / \mathrm{K}$ concentrations in the soil were determined. Alkali-hydrolyzable $\mathrm{N}$ was analyzed by Kjeldahl digestion methods on a Kjeltec 8400 analyzer unit (Foss-Tecator AB, Hoganas, Sweden), available P in plant samples and soils were estimated by molybdovanadate method; whereas available $\mathrm{K}$ was analyzed using an atomic absorption spectrophotometer (Hitachi, Tokyo, Japan).

\section{Experiments on reducing fertilizer application}

The soil was collected from farmland. Soil treatment, PGPR inoculation and planting were the same as in the "Plant growth promotion" section. The experimental treatment included pots with no fertilizer and PGPRs mixture (T1); pots inoculated with PGPRs mixture (T2); pots supplied with $50 \%$ (T3), $75 \%$ (T5) or $100 \%$ fertilizer (T7); pots inoculated with PGPRs mixture and supplied with $50 \%$ (T4) or $75 \%$ fertilizer (T6). The experiment was set up with 8 replicate pots per treatment. The doses of chemical fertilizer were based on a dose commonly used by farmers $\left(105 \mathrm{~kg} \mathrm{~N}, 112.5 \mathrm{~kg} \mathrm{P}_{2} \mathrm{O}_{5}\right.$, and $120 \mathrm{~kg} \mathrm{~K}_{2} \mathrm{O}$ per hectare). Plants were harvested after 3 months, and the fresh weight, dry weight, shoot length, and tiller count of the plants were determined, along with the available $\mathrm{N} / \mathrm{P} / \mathrm{K}$ concentrations of the soil.

\section{Data analyses}

All experiments in the present study were performed in at least three replicates. The data were analysed using SPSS software version 23.0 (Armonk, NY, USA). The significant differences among various treatments were compared using Fisher's protected LSD test with $P \leq$ 0.05 .

\section{Supplementary information}

Supplementary information accompanies this paper at https://doi.org/10. 1186/s12866-020-1708-z.

Additional file 1: Figure S1. Neighbour-joining tree based on 165 rRNA gene sequences of PGPRs.

Additional file 2: Figure S2. The effect of bacterial combination $\mathrm{K} 14+$ $176+\mathrm{P} 9+\mathrm{N} 8+\mathrm{P} 5$ and fertilizer application on N/P/K content in soil. Values are means $\pm S E$. abcd letters on the bars denote differences on the basis of a t-test $(p<0.05)$.

Additional file 3: Identification of bacteria and its promoting effect on plants.

\section{Abbreviations}

ARA: Acetylene reduction activity; IAA: Indole-3-acetic acid; PGPR: Plant growth promoting rhizobacteria; SI: Solubilization index

\section{Acknowledgements \\ Not applicable.}

Authors' contributions

$\mathrm{ZL}$, and $\mathrm{GH}$ make conception and design of this study. RL, JW and $\mathrm{HZ}$ conduct the experiments. ZL carry out the data analysis and manuscript writing. All authors read and approved the final manuscript.

\section{Funding}

This work was supported by the National Key Research and Development Program of China (2018YFD0200403) and natural science basic research plan in shaanxi province of China (2018JM3004). The funders played no role in the design of the study, analysis, and interpretation of data or in writing the manuscript.

\section{Availability of data and materials}

The datasets supporting the conclusions of this article are included within the article. All the bacterial strains can be obtained from the lab of Gehong Wei upon request.

Ethics approval and consent to participate

Not applicable.

Consent for publication

Not applicable.

\section{Competing interests}

The authors declare that they have no competing interests.

\section{Author details}

'State Key Laboratory of Crop Stress Biology in Arid Areas, Northwest A\&F University, Yangling, Shaanxi, China. ${ }^{2}$ Shaanxi Key Laboratory of Agricultural and Environmental Microbiology, College of Life Science, Northwest A\&F University, Yangling, Shaanxi, China. 
Received: 27 September 2019 Accepted: 17 January 2020 Published online: 21 February 2020

\section{References}

1. Hou Y, Ma L, Gao ZL, Wang F, Sims JT, Ma W, Zhang F. The driving forces for nitrogen and phosphorus flows in the food chain of China, 1980 to 2010. J Environ Qual. 2013:42(4):962-71.

2. Sun $B$, Zhang $L$, Yang $L$, Zhang F, Norse D, Zhu Z. Agricultural non-point source pollution in China: causes and mitigation measures. Ambio. 2012 41(4):370-9

3. Zhao X, Zhou Y, Min J, Wang S, Shi W, Xing G. Nitrogen runoff dominates water nitrogen pollution from rice-wheat rotation in the Taihu Lake region of China. Agric Ecosyst Environ. 2012;156:1-11.

4. Anderson KR, Moore PA, Miller DM, Delaune PB, Edwards DR, Kleinman PJ, Cademenun BJ. Phosphorus leaching from soil cores from a twenty-year study evaluating alum treatment of poultry litter. J Environ Qual. 2018;47(3): 530-7.

5. Huang J, Xu C, Ridoutt BG, Wang X, Ren P. Nitrogen and phosphorus losses and eutrophication potential associated with fertilizer application to cropland in China. J Clean Prod. 2017;159:171-9.

6. Wang X, Zou C, Gao X, Guan X, Zhang Y, Shi X, Chen X. Nitrate leaching from open-field and greenhouse vegetable systems in China: a metaanalysis. Environ Sci Pollut Res. 2018;25(31):31007-16.

7. Li XG, Jia B, Lv J, Ma Q, Kuzyakov Y, Li F. Nitrogen fertilization decreases the decomposition of soil organic matter and plant residues in planted soils. Soil Biol Biochem. 2017;112:47-55.

8. Qiao C, Xu B, Han Y, Wang J, Wang X, Liu L, Liu W, Wang S, Tan H, Liu Y, Zhao $X$. Synthetic nitrogen fertilizers alter the soil chemistry, production and quality of tea. A meta-analysis. Agron Sustain Dev. 2018;38(1):10.

9. Villarodriguez E, Parracota Fl, Castrolongoria E, Lopezcervantes J, Santosvillalobos SD. Bacillus subtilis TE3: a promising biological contro agent against Bipolaris sorokiniana, the causal agent of spot blotch in wheat (Triticum turgidum L. subsp. durum). Biol Control. 2019;132:135-43.

10. Cordero I, Balaguer L, Rincon A, Pueyo JJ. Inoculation of tomato plants with selected PGPR represents a feasible alternative to chemical fertilization under salt stress. J Plant Nutr Soil Sci. 2018;181(5):694-703.

11. Emami S, Alikhani HA, Pourbabaei AA, Etesami H, Sarmadian F, Motessharezadeh B. Effect of rhizospheric and endophytic bacteria with multiple plant growth promoting traits on wheat growth. Environ Sci Pollut Res. 2019;26(19):19804-13.

12. Lin L, Li Z, Hu C, Zhang X, Chang S, Yang L, An Q. Plant growth-promoting nitrogen-fixing Enterobacteria are in association with sugarcane plants growing in Guangxi, China. Microbes Environ. 2012;27(4):391-8.

13. Zaheer A, Malik A, Sher A, Qaisrani MM, Mehmood A, Khan SU, Ashraf MU, Mirza Z, Karim S, Rasool M. Isolation, characterization, and effect of phosphate-zinc-solubilizing bacterial strains on chickpea (Cicer arietinum L.) growth. Saudi J Biol Sci. 2019;26(5):1061-7.

14. Matsuda R, Handayani ML, Sasaki H, Takechi K, Takano H, Takio S. Production of indoleacetic acid by strains of the epiphytic bacteria Neptunomonas spp. isolated from the red alga Pyropia yezoensis and the seagrass Zostera marina. Arch Microbiol. 2018;200(2):255-65.

15. Cappellari LD, Santoro MV, Schmidt A, Gershenzon J, Banchio E. Induction of essential oil production in Mentha $\mathrm{x}$ piperita by plant growth promoting bacteria was correlated with an increase in jasmonate and salicylate levels and a higher density of glandular trichomes. Plant Physiol Bioch. 2019;141: 142-53.

16. Sulochana MB, Jayachandra SY, Kumar SA, Parameshwar A, Reddy KM, Dayanand A. Siderophore as a potential plant growth-promoting agent produced by Pseudomonas aeruginosa JAS-25. Appl Biochem Biotech. 2014; 174(1):297-308.

17. Glick BR. Bacteria with ACC deaminase can promote plant growth and help to feed the world. Microbiol Res. 2014;169(1):30-9.

18. Sun G, Yao T, Feng C, Chen L, Li J, Wang L. Identification and biocontrol potential of antagonistic bacteria strains against Sclerotinia sclerotiorum and their growth-promoting effects on Brassica napus. Biol Control. 2017;104:35-43.

19. Etesami H, Emami S, Alikhani HA. Potassium solubilizing bacteria (KSB): mechanisms, promotion of plant growth, and future prospects a review. J Soil Sci Plant Nut. 2017;17(4):897-911.

20. Romeroperdomo F, Abril J, Camelo M, Morenogalvan A, Pastrana I, Rojastapias DF, Bonilla R. Azotobacter chroococcum as a potentially useful bacterial biofertilizer for cotton (Gossypium hirsutum): effect in reducing $\mathrm{N}$ fertilization. Rev Argent Microbiol. 2017:49(4):377-83.

21. Korir H, Mungai NW, Thuita M, Hamba Y, Masso C. Co-inoculation effect of rhizobia and plant growth promoting Rhizobacteria on common bean growth in a low phosphorus soil. Front Plant Sci. 2017;8:141.

22. Huang AC, Jiang T, Liu Y, Bai Y, Reed J, Qu B, Goossens A, Nutzmann H, Bai Y, Osbourn A. A specialized metabolic network selectively modulates Arabidopsis root microbiota. Science. 2019;364(6440):eaau6389.

23. Ali S, Charles TC, Glick BR. Amelioration of high salinity stress damage by plant growth-promoting bacterial endophytes that contain ACC deaminase. Plant Physiol Bioch. 2014;80:160-7.

24. Berendsen RL, Vismans G, Yu K, Song Y, De Jonge R, Burgman WP, Burmolle M, Herschend J, Bakker PAHM, Pieterse CMJ, Pieterse CM. Disease-induced assemblage of a plant-beneficial bacterial consortium. ISME J. 2018;12(6):1496-507.

25. Nakayan P, Hameed A, Singh S, Young L, Hung M, Young C. Phosphatesolubilizing soil yeast Meyerozyma guilliermondii CC1 improves maize (Zea mays L.) productivity and minimizes requisite chemical fertilization. Plant Soil. 2013;373:301-15.

26. Chennappa G, Adkarpurushothama CR, Suraj U, Tamilvendan K, Sreenivasa MY. Pesticide tolerant Azotobacter isolates from paddy growing areas of northern Karnataka, India. World J Microb Biot. 2014;30(1):1-7.

27. Rodelas B, Gonzalez-Lopez J, Pozo C, Salmeron V, Martinez-Toledo MV. Response of faba bean (Vicia faba L.) to combined inoculation with Azotobacter and Rhizobium leguminosarum bv. viceae. Appl Soil Ecol. 1999;12(1):51-9.

28. Shrivastava M, Srivastava PC, D'Souza SF. Phosphate-solubilizing Microbes: diversity and phosphates Solubilization mechanism. Singapore: Role of Rhizospheric Microbes in Soil. Springer; 2018. p. 137-65.

29. Maliha R, Samina K, Najma A, Sadia A, Farooq L. Organic acids production and phosphate solubilization by phosphate solubilizing microorganisms under in vitro conditions. Pak J Biol Sci. 2004;7(2):187-96.

30. Li M, Guo R, Yu F, Chen XY, Zhao H, Li H, Wu J. Indole-3-acetic acid biosynthesis pathways in the plant-beneficial bacterium Arthrobacter pascens ZZ21. Int J Mol Sci. 2018;19(2):443.

31. Kim A, Shahzad R, Kang S, Seo C, Park Y, Park H, Lee I. IAA-producing Klebsiella variicola AY13 reprograms soybean growth during flooding stress. J Crop Sci Biotechnol. 2017;20(4):235-42.

32. Bal HB, Das S, Dangar TK, Adhya TK. ACC deaminase and IAA producing growth promoting bacteria from the rhizosphere soil of tropical rice plants. J Basic Microb. 2013;53(12):972-84.

33. Hao X, Xie P, Johnstone L, Miller SJ, Rensing C, Wei G. Genome sequence and mutational analysis of plant-growth-promoting bacterium Agrobacterium tumefaciens CCNWGS0286 isolated from a zinc-Lead mine tailing. Appl Environ Microbiol. 2012;78(15):5384-94.

34. Etesami $\mathrm{H}$, Alikhani HA. Evaluation of gram-positive rhizosphere and endophytic bacteria for biological control of fungal rice (Oryzia sativa L.) pathogens. Eur J Plant Pathol. 2017;147(1):7-14.

35. Zhang Z, Zhou W, Li H. The role of GA, IAA and BAP in the regulation of in vitro shoot growth and microtuberization in potato. Acta Physiol Plant. 2005;27(3):363-9.

36. Salvo LP, Cellucci GC, Carlino ME, De Salamone IE. Plant growth-promoting rhizobacteria inoculation and nitrogen fertilization increase maize (Zea mays L.) grain yield and modified rhizosphere microbial communities. Appl Soil Ecol. 2018:6:113-20.

37. Robledoburitica J, Aristizaballoaiza JC, Ceballosaguirre N, Cabracendales T. Influence of plant growth-promoting rhizobacteria (PGPR) on blackberry (Rubus glaucus Benth. cv. Thornless) growth under semi-cover and field conditions. Acta Agronómica. 2018;67(2):258-63.

38. Hardy RW, Holsten RD, Jackson EK, Burns RC. The acetylene-ethylene assay for N2 fixation: laboratory and field evaluation. Plant Physiol. 1968;43(8):1185-207.

39. Nautiyal CS. An efficient microbiological growth medium for screening phosphate solubilizing microorganisms. FEMS Microbiol Lett. 1999:170(1):265-70.

40. King EJ. The colorimetric determination of phosphorus. Biochem J. 1932; 26(2):292-7.

41. Setiawati TC, Mutmainnah L. Solubilization of potassium containing mineral by microorganisms from sugarcane Rhizosphere. Agric Agric Sci Proc. 2016:9:108-17.

42. Wilson T, Carson J. Rapid, high-throughput extraction of bacterial genomic DNA from selective-enrichment culture media. Lett Appl Microbiol. 2001;32(5):326-30.

\section{Publisher's Note}

Springer Nature remains neutral with regard to jurisdictional claims in published maps and institutional affiliations. 